\title{
Revelações dos fotógrafos esportivos brasileiros sobre relações de gênero
}

\author{
Revelations of Brazilian sports photographers about gender relations
}

Erik Giuseppe Barbosa Pereira1*, Vanessa Silva Pontes ${ }^{1}$, Carlos Henrique de Vasconcellos Ribeiro ${ }^{2}$

\begin{abstract}
Os objetivos deste estudo são detectar os critérios de registro dos fotógrafos desportivos e analisar seus discursos sobre seus modos de fotografar desportistas masculinos e femininos, problematizando questões de género. Participaram oito fotógrafos desportivos, de diferentes mídias e de ambos os sexos, selecionados aleatoriamente. $O$ instrumento foi uma entrevista semiestruturada e como técnica, utilizamos a análise de discurso. Os discursos dos fotógrafos apresentam contradições, mas aquiescem que é necessário trabalhar em cima de um interesse coletivo.
\end{abstract}

Palavras-chave: Género; Imprensa; Desportos; Discursos.

ABSTRACT

We aimed to detect the photographers' criteria of how to make the portrayal of male and female athletes and analyze their speech regarding the photos registration based on gender hierarchy. Participated ten sports photographers from different medias and both sexes, randomly selected. The instrument was a semi structured interview and as a technique, it was used the discourse analysis. The photographers' speech presents contradictions, but they acquiesce that is necessary to work for a collective interest. Keywords: Gender, Media, Sports, Discourses.

Artigo recebido a 24.03.2014; Aceite 05.06.2014

${ }^{1}$ Escola de Educação Física e Desportos da Universidade Federal do Rio de Janeiro, Brasil

${ }^{2}$ Universidade Gama Filho, Brasil

* Autor correspondente: Av. Carlos Chagas Filho, S/N- Cidade Universitária; 21941-970 Rio de Janeiro, Brasil; E-mail: egiuseppe@eefd.ufrj.br 


\section{INTRODUÇÃO}

O clássico de Scott (1995, p. 75) conceitua género como "forma de indicar "construções culturais" - a criação inteiramente social de ideias sobre os papéis adequados aos homens e às mulheres". Complementa que o termo "tornou-se uma palavra particularmente útil, pois oferece um meio de distinguir a prática sexual dos papéis sexuais atribuídos às mulheres e aos homens".

Seguindo essa esteira historiográfica, Romero (2004, p. 217) elucida que as emergentes "diferenças sexuais foram pretexto para impor relações hierárquicas que apontam para a supremacia e a dominação do homem, aliadas à subordinação da mulher", sendo encontradas nas mais variadas classes, grupos sociais e se perdem através das gerações, abrangendo desde a organização dos espaços, atividades e perpassando as distribuições de poder. Tais relações também são observadas quando debruçamos no universo dos desportos.

A primeira participação feminina oficial em Jogos Olímpicos, desde sua criação em 776 a.C., só ocorreu em 1900. Até então, eram excluídas da participação nos Jogos e seu acesso à prática desportiva era restrito. Miragaya, da Costa, e Turini (2002) esclarece que as únicas imagens femininas datadas dos primórdios dos Jogos referem-se às deusas (Hera, Atena, Afrodite, Ártemis, entre outras), as quais eram retratadas de forma recatada, enfatizando a beleza de suas formas, o sentimentalismo, o cuidado com a natureza e a maternidade. Já os desportistas masculinos, vistos como heróis e/ou semideuses, eram exibidos ostentando uma musculatura bem desenvolvida, considerada protótipo de perfeição, em poses que denotavam poder, força e virilidade. Naquela época, o registro desses ideais restritos de feminilidade e de masculinidade era realizado em esculturas, desenhos, pinturas e mosaicos. No atual contexto, a fotografia emerge como um dos meios que reproduzem essas relações e representações de género.

Desde o seu surgimento, por volta de 1830 , a fotografia vem sendo uma forma de captar momentos vividos, expressões e reações desencadeadas. Segundo Mauad (1996), sua história é marcada por polêmicas relacionadas ao seu uso e finalidade, pois toda representação visual sobrevém de imagens pré-construídas na mente dos que a produzem. Das imagens por eles produzidas, podem se originar múltiplas interpretações, assim como acontece com toda a informação publicada nas mídias, considerando a heterogeneidade de conhecimentos, interpretações e vivências do público alvo (Wolf, 2003).

Compreendendo que a mídia constitui-se em uma forma de pedagogia cultural que ensina maneiras de ver e pensar os desportos (Muhlen, 2008) e que grande parte do ideário social acerca da realidade é pré-formado pelo que se veicula nos meios de comunicação (Alves \& Daldegan, 2012), justificamos o interesse em investigar as questões de género no âmbito da mídia desportiva justamente por ainda se afigurarem como uma lacuna no conhecimento. Romero (2005), no título do seu estudo, traz à tona uma pergunta publicada pela mídia junto à imagem de uma desportista eliminada dos Jogos Pan-Americanos de 2003: "E agora, vão fotografar o que?”. Esta pergunta, enfatizando a principal preocupação do jornalista: a perda de uma musa para estampar as capas dos cadernos desportivos, nos inquietou e inspirou a proceder esta empreitada.

A partir dessas conjecturas e inspirados pelas performatividades midiáticas em tela, objetivamos identificar as intenções dos fotógrafos desportivos no ato do "clic" e sua relação com a hierarquia de géneros no universo desportivo, detectar os critérios de registro dos fotógrafos quanto à forma de retratar desportistas masculinos e femininos e analisar seus discursos acerca desses registros. Seguindo essa linha, delineiam-se as questões norteadoras: Qual o critério dos fotógrafos para registrar corpos masculinos e femininos? Qual a opinião deles diante seu registro?

A fim de elucidá-las, entrevistamos oito atores sociais. Por meio da técnica de análise de discurso, descrita na unidade "Método", 
vislumbramos padrões nas respostas que nos possibilitaram dividir os resultados em duas unidades: 1- Uma questão de lucro, versando sobre quais representações do masculino e feminino representam retorno financeiro e; 2Preferência, Sexismo e Preconceito, na qual discutimos, à luz da hierarquia de géneros, os diferentes critérios adotados pelos fotógrafos para o registro de homens e mulheres nos desportos.

\section{MÉTODO}

Metodologicamente, este estudo, à luz de Gamboa (citado por Faria Jr, 1991), é de natureza qualitativa, inserido na fenomenolgia, utilizando como estratégia a análise de discurso. $\mathrm{O}$ modelo qualitativo proposto por Haguette (1987), Santos Filho e Gamboa (1997) e Demo (2001) busca alastrar as possibilidades de analisar e perceber os fenômenos sociais, ao invés de fecha-los ou concluí-los.

Segundo Santos Filho (citado por Santos Filho \& Gamboa, 1997, pp. 34-35), "a abordagem fenomenológica é holística e tenta por meio da empatia (Einfuhlung) entender os motivos subjacentes às reações humanas". Sabendo que as reações humanas são expressas, dentre outras formas, por meio da fala, buscamos analisar os dados em torno da estratégia da análise de discurso. Nesse caso nos reportamos aos estudos de Orlandi (1987) e Pêcheux (1997) como referências básicas, pois suas convergentes ideias embasaram a construção de nosso corpus metodológico. Nesta trilha de pensamento e especificando neste momento a noção de discurso, consideramos, tendo em conta as ideias de Orlandi (1987, p. 19) apoiadas em Michel Pêcheux, que o discurso constitui o "efeito de sentidos entre interlocutores, enquanto parte do funcionamento social geral. Então, os interlocutores, a situação, o contexto sócio-histórico [...] constituem o sentido da sequência verbal produzida".

\section{Amostra}

A amostra contou com 8 (oito) fotógrafos, de ambos os sexos, escolhidos intencionalmente de forma aleatória em competições realizadas no Estado do Rio de Janeiro. Todos trabalham no referido Estado, no entanto, suas empresas possuem focos diferenciados no que se refere ao público-alvo e aos meios de divulgação: $50 \%$ fotografam para jornais de alta circulação no país e os outros $50 \%$ para jornais locais ou online.

\section{Instrumentos}

$\mathrm{O}$ instrumento empregado foi uma entrevista semiestruturada, a partir dos modos de apreciação dos fotógrafos acerca do "clicar" dos/das desportistas. Para Triviños (1987, p. 152), esse tipo de entrevista "[...] favorece não só a descrição dos fenômenos sociais, mas também sua explicação e a compreensão de sua totalidade, tanto dentro de sua situação específica como de sua situação de dimensões maiores". O roteiro da entrevista compreendeu 19 questões abertas e fechadas que versavam sobre os critérios e preferências de seus registros de fotos masculinas e femininas nos desportos. A partir daí, pudemos detectar critérios de registro dos fotógrafos nas fotos de desportistas masculinos e femininos; e analisar o discurso dos fotógrafos desportivos sob a ótica da hierarquia de género.

\section{Procedimentos}

Após postulados os objetivos e questões intrigantes, buscamos, em duas competições e em duas sedes administrativas de jornais de grande circulação, repórteres fotográficos especializados em eventos desportivos. Os mesmos autorizaram a consecução da entrevista mediande assinatura do Termo de Compromisso Livre e Esclarecido (TCLE) e a mesma foi efetivada mediante aplicativo de gravador de audio instalado em celular do tipo smartphone com sistema operacional Android 2.3. Vale ressaltar que o estudo foi avaliado e aprovado pelo Comitê de Ética em Pesquisa do Hospital Universitário Clementino Fraga Filho (HUCFF/UFRJ), sendo o número do parecer 517.204 e o protocolo 26913 , grupo III.

A nossa estratégia de análise dos dados circunscreve-se sob a perspectiva de análise de discurso. Sendo assim, pretendemos, na esteira de 
Lima (1994, pp. 64-65), utilizar como mecanismos do processo de análise de dados as seguintes etapas: 1- Descrição: "Retirada do discurso da fita cassete [sic] sem alterar uma única palavra [...]"; 2- Redução fenomenológica: $\mathrm{Na}$ qual "o pesquisador julga mais significativo determinadas unidades e as destaca do discurso para análise. É a busca do essencial [...]. Isto é, frases revelatórias"; 3- Reorganização das unidades: Após a $2^{\mathrm{a}}$ etapa, "alguns discursos necessitam de uma reorganização das unidades, pois muitas delas convergem entre si, falam sobre o mesmo assunto, ainda são convergências dentro do próprio discurso"; 4- Interpretação fenomenológica: Passada a $3^{\text {a }}$ etapa, realizamos a "transformação das expressões cotidianas [...] numa linguagem adequada, com ênfase no fenômeno que está sendo investigado".

\section{RESULTADOS}

Para facilitar a compreensão dos resultados, selecionamos e dividimos os discursos mais significativos em duas unidades: 'Uma questão de lucro' e 'Preferência, sexismo e preconceito'. Em ambas, as falas proferidas pelos entrevistados aparecerão numeradas, o que facilitará o entendimento das posteriores análises.

\section{Uma questão de lucro}

Fala 1. Entrevistado C.L.: "[...] se tiver um negócio chamando muita atenção. Se tiver com uma roupa nova, é isso que a gente vai fazer. Se não a gente procura alguma coisa. Então, isso que é jornalismo, isso".

Fala 1. Entrevistado O.V.: "Porra [sic], a sociedade quer ver tudo, quer ver tudo. $E$ a gente vai ter vezes que tem que mostrar né? [...] dentro do esporte [sic] a gente pega o que tem que pegar [...] pode tá de qualquer jeito, um gesto obsceno a gente também manda a ver".

Fala 1. Entrevistado R.A.: "[...] já tá mais do que provado que a indústria do sexo é a que mais vende. Então, as pessoas cada vez mais exploram isso, não só profissionalmente. [...] É, a sociedade que pede, porque se não, não era consumido, concorda?".
Fala 2. Entrevistado R.A.: "Olha a mídia em geral ela [balbuciou] Ela explora o que vende [...]. Eu acho que o fotógrafo tem que ser sensivel ao ponto de saber o que é notícia e o que ele pode vender. Então, o cara partindo do princípio que a sensualidade vende, ele tem que ter a sensibilidade de fotografar aquele momento, de pegar aquele momento e, na medida do possível, colocar isso na mídia, né [Pausa] Ou vender isso. É claro, de uma maneira elegante, nunca pejorativa".

Fala 3. Entrevistado R.A.: "[...] É o diretor de arte quem determina que foto vai ser [Pausa] Então, se uma foto mais sensual de uma jogadora de vôlei ele entender que vai vender mais, é aquela foto que vai pro jornal, entendeu?".

Fala 1. Entrevistado J.W.: "Vende mais a imagem da mulher com aquela coisa feminina né? É legal. E não pode ir pra casa sem fotografar isso".

Fala 1. Entrevistado P.K.: "Na verdade, quando a gente tira é mais assim: 'Pô, achei que as meninas são bonitas', a gente fica admirando. Se bota na internet e vende, pro profissional é melhor, né?[sic] Mas, não tem, assim, uma regra, porque que a gente faz isso [...]. Agora, por exemplo, os caras de natação, você agora nas Olimpíadas [...] consegue ver, todos eles são explorados, porque tá [sic] sem camisa, abdome sempre rachado [sic] [Pausa] Você vê até galeria na internet de foto de abdome [sic] [Pausa] Qual o mais definido? Antigamente tinha mais bunda de mulher, hoje já consegue ver abdome (de homens)".

\section{Preferência, sexismo e preconceito}

Esta unidade reúne discursos centrados na questão do critério de registro, da beleza atrelada ao desporto e da mídia como (re)produtora da masculinidade e da feminilidade.

O sexismo e a preferência pelo desporto feminino foram evidenciados pela maior parte dos entrevistados do sexo masculino. O primeiro discurso proferido por R.A. foi por nós elencado como o mais representativo dessa temática 
Indo ao encontro das ideias de Miragaya et al. (2002), Knijnik (2003) e Goellner (2006), a entrevistada J.G.S., em sua primeira alocução, sugere que é natural ao homem se apresentar extenuado para as fotos, o que confirma a existência de um padrão de valorização e tendência à exaltação pelo esforço depreendido em função dos feitos masculinos. Em contrapartida, o que se tem como normal para o comportamento feminino é que ela busque se recuperar após esforços físicos, a fim de que sua beleza seja mostrada. Já o entrevistado O.V. discorda desse ponto de vista em seu primeiro pronunciamento.

Avançando em nossos achados, à luz de Goellner (2006) e Tralci Filho e Rubio (2012), os discursos 2 de O.V., 1 de P.K. e 1 de J.W. reforçam que a "permissividade" social à prática desportiva pelas mulheres encontra barreira na manutenção de uma "essência feminina", diga-se de passagem, a beleza. Essa barreira é, sobretudo, (re)criada pelos discursos e imagens que circulam na mídia.

O autor Knijnik (2003) e as autoras Silva, Botelho-Gomes e Goellner (2008) afirmam que embora as mulheres enfrentem ambientes inóspitos no desporto, os homens também sofrem inibições de comportamento e padrões corporais, para que sua virilidade não seja posta em xeque. Ainda segundo estes, as desportistas que se aventuram nas práticas inadequadas ao feminino são frequentemente taxadas de "sapatão". E, para os homens, a lógica é a mesma: os taxamentos giram em torno do termo pejorativo "paneleiro".

Segundo Freitas (2002) os editores publicam, de acordo com sua opinião, matérias sobre homens e mulheres valorizando-os ou não. A imprensa tem o poder de ascender $o$ desportista ou difamar sua imagem. Sobre essa temática é frisada por R.A. em seu segundo e terceiro discursos. Ele também reforça o quanto as identidades de gênero podem ser utilizadas como elementos evidenciadores ou difamadores de um atleta, na medida em que o mesmo se encontra ou não nos moldes hegemônicos.
Conforme Sancho, Herraiz, Hernández e Vidiella (2010), o significado social do futebol para a mídia, assim como o das lutas, é o de fomentar diferenças hierárquicas na construção do género, tendo-se convertido em fenômenos e universos masculinizantes.

O clássico de Sabo (2002) conceitua as identidades de género "masculinidade hegemônica" e da "feminilidade enfatizada" como mais valorizadas num determinado momento histórico, representando o ideal cultural mais notável para homens e mulheres. Esse binarismo macho/fêmea (masculino/feminino) vigora nas práticas corporais e nos desportos, não abrindo precedentes para variações (Knijnik, 2010). O desporto, nessa esteira, vem ajudando a arquitetar e sustentar os estereótipos de masculinidade e feminilidade hegemônicas, determinando o que homens e mulheres podem - e devem - fazer. Dessa maneira, todo comportamento divergente do esperado para os indivídios de ambos os sexos vai de encontro à homofobia e discriminação (Gomes, Silva, \& Queirós, 2008).

Segundo Andrade, Romero e Pereira (2011), Andrade, Bôas, Romero e Pereira (2012) e Almeida e Soares (2012), desde seu surgimento, o futebol é considerado um desporto viril, templo de culto à masculinidade. Jogadores que não se enquadram nesse padrão são hostilizados publicamente, pois seus comportamentos são vistos como desviantes e incomuns ou inesperados. Atribuímos isso pelo futebol possuir larga difusão midiática, o que lhe confere importante papel normalizador da masculinidade heterocentrada, impondo-lhe rígidas regras (Fausto-Sterling, 2006 citado por Sancho et al., 2010).

Amaral (2007), citado por Almeida e Soares (2012, p. 309), destaca a fala de um Juiz de Direito, no qual a autoridade judicial confirma essa visão:

Quem se recorda da 'copa do mundo de 1970' [...], jamais conceberia um ídolo seu homossexual [...]. Quem vivenciou grandes orquestras futebolísticas [...] não poderia 
sonhar em vivenciar um homossexual jogando futebol [...]. Não que um homossexual não possa jogar bola [...]. Mas forme o seu time e inicie uma Federação [...]. O que não se mostra razoável é a aceitação de homossexuais no futebol brasileiro, porque prejudicam a uniformidade do pensamento da equipe, o entrosamento, o equilíbrio, o ideal $[. .$.$] .$

Wolf (1997, 2003) elucida que o monopólio e hierarquização dos acontecimentos por um sujeito determinam de que forma os espectadores interpretarão aquilo que lhes é transmitido. Ainda segundo o autor, os meios de comunicação possuem antagônicos poderes de influência, podendo aumentar ou reduzir a importância e o significado daquilo que é transmitido. No caso, o futebol está culturalmente enraizado na nossa sociedade, e em se tratando do masculino, este é muito mais divulgado pelos media do que o feminino. J.W. confirma essa invisibilidade feminina nos campos em sua segunda e irônica fala.

Conforme Muhlen (2010, p. 9), corpos belos são postos à mostra, mas há "diferenciações sobre o que se deve mostrar de cada corpo". A diferença não é apenas entre corpos femininos e masculinos, mas o que se deixa/pode ver de cada um desses corpos. R.A. e J.W., em seus quarto e terceiro discursos, respetivamente, enfatizam essas diferenças no lugar simbólico das representações corpóreas femininas e masculinas. Corroborando com essa ideia, o entrevistado P.K. desvenda em sua segunda fala a real forma de retratar as equipes masculina e feminina de Voleibol, contradizendo, inclusive, seu discurso transcrito na unidade anterior.

O corpo masculino, quando exposto sugerindo algum tipo de apelo, é representado de forma diferenciada, não vexatória ou pejorativa e sempre em posição de altivez. Já para o feminino o apelo é sexualizante, com enfoques completamente distoantes da faceta desportiva. Vemos esses fatores como a causa da invisibilidade feminina no âmbito desportivo, podendo ainda estabelecer uma relação, na esteira de Betti $(2001,2005)$ e
Mineiro (2010), com a escassa cobertura da imprensa aos eventos desportivos femininos, posto que isto "reflete não só as crenças culturais existentes que associam os desportos com a masculinidade, mas também reproduzem uma hierarquia institucional na qual os homens dominam e controlam aquilo que se discute na mídia esportiva [sic] [...]" (Sabo, 2002, p. 35).

\section{CONCLUSÕES}

Estabelece-se uma correlação entre o retratamento na Grécia Antiga e o enquadramento diferenciado por géneros utilizado pela mídia na sociedade contemporânea. A beleza já não é mais um atributo exclusivo dos deuses. O corpo é uma construção cultural em constante mutação, no entanto, a imprensa continua a manter a subordinação feminina frente à supervalorização do homem no desporto.

Constatamos que os fotógrafos focam o corpo feminino belo e sensual em detrimento da representação de seu movimento no desporto, o que explica a ocorrência de mais fotos de mulheres desportistas apresentando conotação sexual. Sua performance é relegada a segundo plano e o que lhe resta é desfilar sua imagem, quando bela, aos olhos da mídia, na frente das lentes dos fotógrafos. Conforme Devide, Lima, Rodrigues, e Batista (2008), Muhlen (2008, 2009, 2010), Muhlen e Goellner (2012) e Romero $(2004,2005)$, e diante do exposto, temos a contestação de que a mulher não recebe o mesmo tratamento dado ao homem pela imprensa desportiva, uma vez que o apelo estético e sexual feminino é enaltecido e, ainda assim, isso só ocorre se sua beleza estiver em conformidade com os padrões convencionados e preestabelecidos pela própria mídia, que a enxerga como sexo frágil.

Verificamos que o publicado nos jornais não condiz com os discursos proferidos pelos entrevistados, uma vez que em diversos momentos afirmaram não haver discrepâncias quanto ao registro do masculino e do feminino. $\mathrm{Na}$ esteira de Romero (2005), a imprensa desportiva age de forma tendenciosa no que se 
refere aos registros fotográficos de desportistas masculinos e femininos. Os fotógrafos, de certa forma, evitam falar sobre o caso e se utilizam de respostas evasivas para se esquivar de questões de género, o que fica fortemente evidenciado nos discursos do entrevistado R.A. sobre a larga exploração da sexualidade pela mídia.

Seguindo a égide de Romero, Miragaya, Ribeiro e Pereira (2014), o falado muitas vezes não corresponde ao clicado, o que é facilmente visualizado ao contrastarmos as imagens publicadas nos jornais com os discursos expostos. $\mathrm{Na}$ grande maioria das imagens publicadas de desportistas do sexo feminino, o retratamento é feito de costas, evidenciando glúteos, e raramente aparecem imagens delas suadas e/ou despenteadas. Já o homem é retratado pondo-se em evidência a agressividade, a competitividade, a força e a resistência emocional, sendo fotografados, na maioria das ocasiões, durante a execução de gestos técnicos, no auge da performance ou no momento decisivo de uma partida. A partir dessa perspectiva e tendo em vista que é frequente essa forma de retratação, depreendemos que o sexismo $\mathrm{e}$ as desigualdades de género estão presentes não só nas desveladas discrepâncias na forma de representação do masculino e do feminino, como também nos discursos proferidos pelos fótografos que produziram essas imagens sobre os critérios adotados pela mídia desportiva para (re)afirmar estereótipos presentes na sociedade.

Corroborando com Muhlen (2008, 2010), a imprensa ensina várias formas de olhar o corpo e esse olhar é oriundo de uma cultura patriarcal. Sendo a mídia uma instituição generificada e a imprensa desportiva uma reserva de dominação masculina, os discursos e representações que circulam acerca do corpo dessas desportistas buscam destacar seus atributos físicos centrando-os numa política de erotização, de fetiche, como uma mercadoria de consumo.

Ao que tudo indica, as desportistas se sentem mais à vontade quando fotografadas por uma mulher. Isto é comprovado ao compararmos os discursos de dois fotógrafos, um do sexo feminino e o outro do sexo masculino (J.G.S e O.V.). Encontrando guarida nas pausas, concluímos que os fotógrafos homens revelam uma visão preconceituosa com relação às feminilidades que não se enquadram naquela que é tida como a ideal para as mulheres. As páginas dedicadas ao desporto na mídia escrita pertencem e se dedicam a uma reserva masculina heteronormativa. $\mathrm{O}$ poder exercido pela imprensa atua na manutenção das desigualdades sociais e na reprodução dos estereótipos, machismos e preconceitos dominantes para com as identidades de género desviantes da hegemônica (Romero et al., 2014).

Não consideramos os diferentes contextos sócio-histórico-culturais dos quais provieram os entrevistados. As contradições evidenciadas estão relacionadas à categoria profissional. Constatamos que os discursos midiáticos, particularmente dos fotógrafos desportivos, contradizem-se, uma vez que, ao mesmo tempo em que dizem não haver divergências nos registros, também afirmam preferir e achar mais confortável fotografar mulheres a homens. Convém ressaltar que a preferência e o sexismo foram detectados nos discursos dos entrevistados do sexo masculino, os quais demonstraram desconforto ao abordar questões de género nos desportos, enquanto que as entrevistadas não declararam prioridade alguma.

Finalizando, averiguamos ser importante investigar as intenções dos superiores dos atores sociais do presente estudo, os editoreschefes, sugerindo esta abordagem aos estudos futuros que complementem e contribuam para a temática do género na imprensa desportiva.

Agradecimentos:

Nada a declarar.

Conflito de Interesses:

Nada a declarar. 
Financiamento:

Nada a declarar.

\section{REFERÊNCIAS}

Almeida, M. B., \& Soares, A. da S. (2012). O futebol no banco dos réus: caso da homofobia. Movimento, 18(1), 301-321.

Alves, C. A., \& Daldegan, M. C. (2012). «Diários secretos»: uma análise da visibilidade sobre o escândalo na assembleia do Paraná nas capas da gazeta do povo. Ação Midiática - Estudos em Comunicação, Sociedade e Cultura., 1(1), 7691. http://doi.org/10.5380/am.v0i1.25706

Andrade, G. M., Bôas, M. F. C. V., Romero, E., \& Pereira, E. G. B. (2012). "Até pode ter, mas não precisa demonstrar ou assumir! Ninguém precisa saber!»: Discursos dos alunos de educação física sobre as masculinidades do futebol. FIEP Bulletin On-line, 82(1), 1-7.

Andrade, G. M., Romero, E., \& Pereira, E. G. B. (2011). As masculinidades no futebol: O que falam e como veem os alunos de Educação Física. Coleção Pesquisa em Educação Física, 10(5), 37-44.

Betti, M. (2001). Esporte na mídia ou esporte da mídia? Motrivivência, O(17), 1-3.

Betti, M. (2005). Esporte, entretenimento e mídias: implicações para uma política de esporte e lazer. Impulso, 16(39), 83-89.

Demo, P. (2001). Pesquisa e informação qualitativa ( $3^{\text {a }}$ ed.). Campinas, São Paulo: Papirus Editora.

Devide, F. P., Lima, F. R., Rodrigues, F. S. J., \& Batista, R. S. (2008). Produção de sentidos sobre a visibilidade de mulheres atletas no jornalismo esportivo: interpretações a partir do Caderno de Esporte do Jornal «O Globo». Em E. Romero \& E. G. B. Pereira (Eds.), Universo do corpo: masculinidades e feminilidades (pp. 401-416). Rio de Janeiro: Shape.

Faria Jr, A. G. (1991). Pesquisa em Educação Física: enfoques e paradigmas. Em A. G. Faria Jr \& P. T. Farinatti (Eds.), Pesquisa e produção do conhecimento em educação física: SBDEF (pp. 1333). Rio de Janeiro: Ao livro Técnico.

Freitas, S. G. (2002). Mulher: Fonte e instrumento de poder. Em A. C. Simões (Ed.), Mulher e Esporte - Mitos e Verdades (pp. 49-68). São Paulo: Manole.

Goellner, S. (2006). Entre o sexo, a beleza e a saúde: o esporte e a cultura fitness. Labrys. Estudos Feministas, 10, 12.

Gomes, P. B., Silva, P., \& Queirós, P. (2008). Distintos registros sobre o corpo feminino: beleza, desporto e mídia. Em E. Romero \& E. G. B. Pereira (Eds.), Universo do corpo: masculinidades e feminilidades (pp. 387-400). Rio de Janeiro: Shape.

Haguette, T. M. F. (1987). Metodologias qualitativas na sociologia. Petrópolis: Vozes.

Knijnik, J. D. (2003). A mulher brasileira e o esporte: seu corpo, sua história. São Paulo: Editora Mackenzie.

Knijnik, J. D. (Ed.). (2010). Gênero e esporte: masculinidades \& feminilidades. Rio de Janeiro: Apicuri.

Lima, L. A. (1994). Capoeira angola: lição de vida na civilização brasileira. Em M. A. Bicudo \& V. H. Esposito (Eds.), Pesquisa qualitativa em educação: um enfoque fenomenológico (pp. 61-66). Piracicaba: Editora Unimep.

Mauad, A. M. (1996). Através Da Imagem: Fotografia e História Interfaces. Tempo, 1(2), 73-98.

Mineiro, D. S. (2010). Esporte, mulher e mídia: Análise do espaço e tratamento dado ao futebol feminino nos portais Globo.com, Estadão e UOL, em dois períodos distintos, setembro de 2007 e agosto de 2009 (Monografia do Curso de Comunicação Social). Centro Universitário de Belo Horizonte, UNI-BH, Belo Horizonte, Brasil.

Miragaya, A. (2002). A mulher olímpica: tradição versus inovação na busca pela inclusão. Em L. P. da Costa \& M. Turini (Eds.), Coletânea de textos em estudos olímpicos (Vol. 1, pp. 763- 792). Rio de Janeiro: Gama Filho.

Muhlen, J. C. V. (2008). Pan-Americano Rio 2007: Análise dos discursos sobre gênero e sexualidade produzidos pela mídia esportiva. Em XII Congresso de Educação Física e Ciências do Desporto dos países de Língua Portuguesa. Porto Alegre, RS.

Muhlen, J. C. V. (2009). Esporte e Mídia: Representações de gênero para atletas no Pan-Americano Rio 2007. Em IV Seminário Corpo, Gênero e Sexualidade. Composiçôes e desafios à formação docente. Universidade Federal do Rio Grande, Rio Grande.

Muhlen, J. C. V. (2010). Musos e musas: a beleza dos atletas «rouba a cena» nos Jogos Olímpicos de Pequim. Em Anais do Seminário Internacional Fazendo Gênero 9. Florianópolis, Brasil.

Muhlen, J. C. V., \& Goellner, S. V. (2012). «Gender game» in Beinjing 2008: representation of femininities and masculinities (re)produced by Terra website. Revista Brasileira de Ciências do Esporte, 34(1), 165-184. http://doi.org/10.1590/S010132892012000100012

Orlandi, E. P. (1987). A linguagem e seu funcionamento: as formas do discurso. Campinas, São Paulo: Pontes.

Pêcheux, M. (1997). O Discurso: estrutura ou acontecimento. (E. P. Orlandi, Trad.). Campinas, SP: Pontes.

Romero, E. (2004). (In)visibilidade da mulher atleta no jornalismo esportivo do Rio de Janeiro. Em 
A. C. Simões \& J. D. Knijnik (Eds.), O mundo psicossocial da mulher no esporte: comportamento, gênero, desempenho (pp. 213-252). São Paulo: Editora Aleph.

Romero, E. (2005). E agora, vão fotografar o quê? As mulheres no esporte de alto rendimento. $\mathrm{La}$ brys. Estudos Feministas, 8, 1-29.

Romero, E., Miragaya, A., Ribeiro, C., \& Pereira, E. (2014). O olhar da imprensa sobre o vôlei feminino: quando a sombra se destaca. Revista Salusvita, 33(1), 17-44.

Sabo, D. (2002). O estudo crítico das masculinidades. Em M. Adelman, C. B. Silvestrin, \& G. L. Louro (Eds.), Coletânea gênero plural: um debate interdisciplinar (pp. 33-46). Curitiba: Editora UFPR.

Sancho, J. M., Herraiz, F., Hernandez, F., \& Vidiella, J. (2010). Masculinidade hegemônica, esportes e atividade física. Movimento, 16(4), 93-115.

Santos Filho, J. C., \& Gamboa, S. S. (Eds.). (1997). Pesquisa educacional: qualidade-quantidade. São Paulo: Cortez Editora.
Scott, J. (1995). Gênero: uma categoria útil de análise histórica. Educação \& Realidade, 20(2), 71-99.

Silva, P., Botelho-Gomes, P., \& Goellner, S. V. (2008). Educação Física no sistema educativo português: um espaço de reafirmação da masculinidade hegemônica. Revista Brasileira de Educação Física e Esporte, 22(3), 219-233. http://doi.org/10.1590/S180755092008000300006

Tralci Filho, M. A. T., \& Rubio, K. (2012). As identidades da atleta brasileira: os "pontos de apego temporários» da mulher na vida esportiva. $\mathrm{Mo}$ vimento, 18(2), 255-275.

Triviños, A. N. S. (1987). Introdução à pesquisa em ciências sociais: a pesquisa qualitativa em educação. São Paulo, Brasil: Atlas.

Wolf, M. (1997). Las influencias discretas. CIC Cuadernos de Información y Comunicación, (3), 243-256.

Wolf, M. (2003). Teorias da comunicação. Lisboa: Presença.

Todo o conteúdo da revista Motricidade está licenciado sob a Creative Commons, exceto quando especificado em contrário e nos conteúdos retirados de outras fontes bibliográficas. 